\title{
The Positional Effect of Solute Functional Group among Positional Isomers of Phenylpropanol in Hydroxyl Group-Solvent Specific Interactions in Methanol/Water Mixed Solvents Monitored by HPLC
}

\author{
Won Jo Cheong, Joung Ho Ko, and Gyoung Won Kang \\ Department of Chemistry and Institute of Basic Research, Inha University, Incheon 402-751, Korea \\ *E-mail: wjcheong@inha.ac.kr \\ Received March 21, 2005
}

\begin{abstract}
We have evaluated the hydroxyl group-solvent specific interactions by using a Lichrosorb RP18 stationary phase and by measuring the retention data of carefully selected solutes in 50/50, 60/40, 70/30, 80/20, and 90/ $10(\mathrm{v} / \mathrm{v} \%)$ methanol/water eluents at $25,30,35,40,45$, and $50{ }^{\circ} \mathrm{C}$. The selected solutes are 3 positional isomers of phenylpropanol, that is, 1-phenyl-1-propanol, 1-phenyl-2-propanol, and 3-phenyl-1-propanol. There exist clear discrepancies in $\Delta \mathrm{H}^{\mathrm{o}}$ (solute transfer enthalpy from the mobile to the stationary phase) and $\mathrm{T} \Delta \mathrm{S}^{\mathrm{o}}$ (solute transfer entropy) among positional isomers. The difference in $\Delta \mathrm{H}^{\circ}$ and $\mathrm{T} \Delta \mathrm{S}^{\circ}$ between secondary alcohols (1phenyl-1-propanol and 1-phenyl-2-propanol)is negligible compared to the difference between the primary alcohol (1-phenyl-3-propanol) and secondary alcohols. The $\mathrm{T} \Delta \mathrm{S}^{\mathrm{o}}$ values of 3-phenyl-1-propanol are close to those of butylbenzene while the $\mathrm{T} \Delta \mathrm{S}^{\circ}$ values of secondary alcohols are close to those of propylbenzene. The difference in $\Delta \Delta \mathrm{H}^{\circ}$ (specific solute-mobile phase interaction enthalpy) between the primary alcohol and the secondary alcohol decreases with increase of methanol content in the mobile phase. A unique observation is an extremum for 1-phenyl-3-propanol in the plot of $\mathrm{T} \Delta \Delta \mathrm{S}^{\circ} v s$. methanol volume \%. The positive sign of $\mathrm{T} \Delta \Delta \mathrm{S}^{\circ}$ of 3-phenyl-1-propanol implies that the entropy of 3-phenyl-1-propanol is greater than that of the hypothetical alkylbenzene (the same size and shape as phenylpropanol) in the mobile phase.
\end{abstract}

Key Words : Phenylpropanol, Hydroxyl group, Positional effect, Specific interaction

\section{Introduction}

Chromatography is useful to obtain information on solutesolvent thermodynamic interactions. Such information can be obtained by measuring retention data over a wide range of temperature. ${ }^{1-13}$ In some of our previous reports, ${ }^{14-15}$ we showed that the carbonyl group-solvent specific interaction of acetophenone in aqueous methanol mixtures is much stronger than the hydroxyl group-solvent specific interaction of phenol by measuring solute retention on a squalane impregnated $\mathrm{C}_{18}$ phase. We proposed accessibility of solvent molecules to the solute functional group as the criterion for determining the magnitude of specific solute-solvent interaction. In later reports, ${ }^{16-17}$ we confirmed that spatial accessibility is a very crucial factor to the specific functional group-solvent interaction by comparing such interactions in acetonitrile/water mixed solvents among solutes of different functional group accessibilities, for example phenol $v s$. benzylalcohol and acetophenone $v s$. benzylacetone.

Recently, we showed that there exist clear discrepancies in solute-solvent specific interactions among positional isomers of phenylbutanols in aqueous methanol mixtures ${ }^{18}$ using an Alltima $\mathrm{C}_{18}$ stationary phase. In this study, we examined differences in functional group-solvent interactions among positional isomers of phenylpropanols in aqueous methanol mixtures using a Lichrosorb RP18 stationary phase.

The enthalpy and entropy of solute transfer from the mobile to the stationary phase are easily obtained from the slope and intercept in the van't Hoff plot (ln $k^{\prime} v s$. 1/T, $k^{\prime}$ : capacity factor). If we consider a pair of polar and nonpolar solutes which are of the same size and shape except for a polar functional group, the enthalpy of specific functional group-mobile phase interaction can be obtained only by subtracting the solute transfer enthalpy of the nonpolar solute from that of the polar solute. ${ }^{14}$

\section{Experimental Section}

Methanol and water were of HPLC grade and purchased from Fisher (Pittsburg, USA) and used without further purification. The selected solutes (propylbenzene, butylbenzene, 1-phenyl-1-propanol, 1-phenyl-2-propanol, 3-phenyl1-propanol) were purchased from Aldrich (Milwaukee, IL, USA) and used without purification.

The experimental details were basically the same as those in the previous reports. ${ }^{18}$

The mobile phase used were methanol/water mixtures (50/ $50,60 / 40,70 / 30,80 / 20,90 / 10 \mathrm{v} / \mathrm{v} \%$ ) and the flow rate was fixed at $1 \mathrm{~mL} / \mathrm{min}$. The solute retention data were collected at $25,30,35,40,45$, and $50{ }^{\circ} \mathrm{C} . \mathrm{KNO}_{3}$ was used as the void volume marker.

More than two independent measurements on different days were made to calculate the thermodynamic properties. When the difference between the two measurements was larger than 5\%, additional measurements were made. In order to estimate retention data of a hypothetical nonpolar 
solute whose intrinsic volume is the same as that of its polar counterpart, we measured retention data of two alkylbenzenes on condition that the intrinsic volume of the polar solute lies between those of the alkylbenzenes. The capacity factor of the hypothetical nonpolar solute was calculated based on the retention data of the two alkylbenzenes.

\section{Results and Discussion}

The measured solute transfer enthalpies and entropies from the mobile to the $\mathrm{C}_{18}$ stationary phase and their standard deviations for all the solutes are summarized in Table 1, The variation trends of solute transfer enthalpies and entropies for phenylpropanol isomers with respect to mobile phase composition are compared in Figures 1 and 2.

The solute transfer enthalpies and entropies from the mobile phase to the $\mathrm{C18}$ phase. From the results, we can easily note that the solute transfer from the mobile to the stationary phase is enthalpically favorable (-sign) and entropically unfavorable (-sign) and that the enthalpic contribution $\left(\Delta \mathrm{H}^{\circ}\right)$ is predominate over the entropic contribution $\left(-\mathrm{T} \Delta \mathrm{S}^{\circ}\right)$. The increasing trend of absolute value of $\Delta \mathrm{H}^{\circ}$ and $\mathrm{T} \Delta \mathrm{S}^{\circ}$ (Figures 1 and 2) with increase of water content in the mobile phase is a general phenomenon in reversed phase liquid chromatography owing to increasing solute cavity formation energy with increase of water content in the mobile phase.

The molecular size of phenylpropanol is larger than the size of propylbenzene and smaller than the size of butylbenzene. The $\Delta \mathrm{H}^{\mathrm{o}}$ values of phenylpropanol isomers, however, are not located between the $\Delta \mathrm{H}^{\circ}$ values of propylbenzene and butylbenzene, but located far away from the $\Delta \mathrm{H}^{\mathrm{o}}$ values of propylbenzene and butylbenzene (Figure $1)$. This is because there exist dispersive and specific solute- solvent interactions in the mobile phase for phenylpropanol isomers while there is only dispersive interaction for propylbenzene and butylbenzene. On the other hand, the $\mathrm{T} \Delta \mathrm{S}^{\mathrm{o}}$ values of phenylpropanol isomers are located near the $\mathrm{T} \Delta \mathrm{S}^{\mathrm{o}}$ values of propylbenzene and butylbenzene (Figure 2). This means that the specific interaction does not significantly induce entropy change.

There exist clear discrepancies in $\Delta \mathrm{H}^{\circ}$ and $\mathrm{T} \Delta \mathrm{S}^{\circ}$ among positional isomers as expected from the results of previous

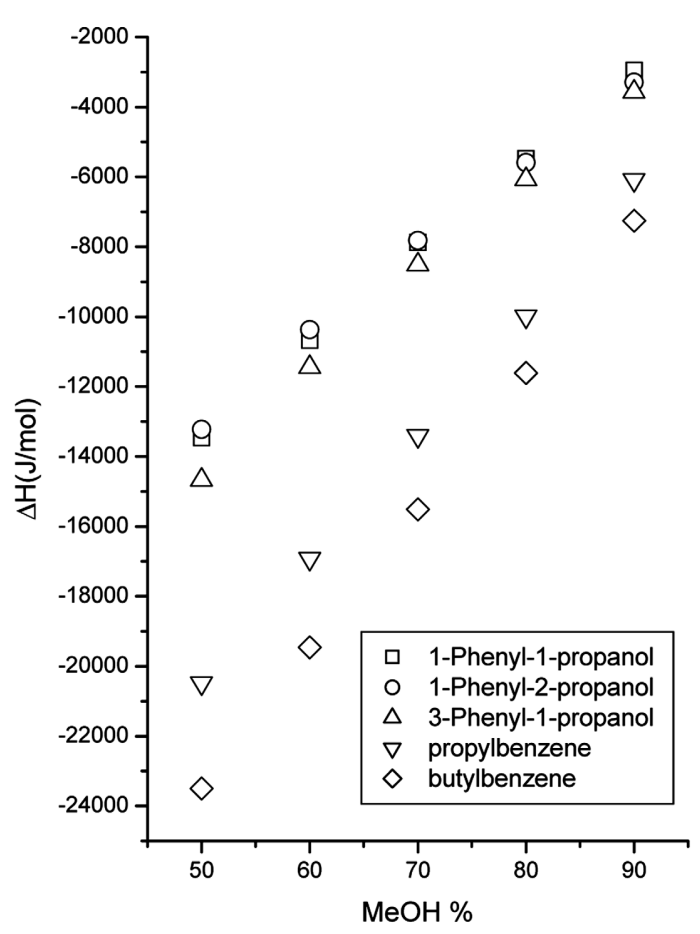

Figure 1. The solute transfer enthalpies.

Table 1. The solute transfer enthalpies $\left(\Delta \mathrm{H}^{\circ}\right)$ with their standard deviations in comparison with the solute transfer entropies $\left(\Delta \mathrm{S}^{\circ}\right)$ times temperature $\left(308.15^{\circ} \mathrm{K}\right)$ given in parentheses and the solute transfer free energy (based on the relationship $\Delta \mathrm{G}^{\mathrm{o}}=\Delta \mathrm{H}^{\mathrm{o}}-\mathrm{T} \Delta \mathrm{S}^{\mathrm{o}}$, denoted by an asterisk) from the mobile phase to the stationary phase obtained by the $\mathrm{C}_{18}$ stationary phase ${ }^{a}$ (Unit: $\mathrm{J} / \mathrm{mol}$ )

\begin{tabular}{|c|c|c|c|c|c|}
\hline \multirow{2}{*}{ Solute } & \multicolumn{5}{|c|}{ Mobile phase (MeOH\%) } \\
\hline & & 60 & 70 & 80 & 90 \\
\hline 1-phenyl-1-propanol & $\begin{array}{c}-13500 \pm 20 \\
(-8500 \pm 20) \\
-5000^{*}\end{array}$ & $\begin{array}{c}-10700 \pm 50 \\
(-7600 \pm 60) \\
-3100^{*}\end{array}$ & $\begin{array}{c}-7900 \pm 150 \\
(-6500 \pm 140) \\
-1400^{*}\end{array}$ & $\begin{array}{c}-5500 \pm 70 \\
(-5700 \pm 60) \\
200^{*}\end{array}$ & $\begin{array}{c}-3000 \pm 190 \\
(-4700 \pm 200) \\
1700^{*}\end{array}$ \\
\hline 1-phenyl-2-propanol & $\begin{array}{c}-13200 \pm 10 \\
(-8700 \pm 50) \\
-4500^{*}\end{array}$ & $\begin{array}{c}-10400 \pm 90 \\
(-7600 \pm 80) \\
-2800^{*}\end{array}$ & $\begin{array}{c}-7800 \pm 160 \\
(-6600 \pm 160) \\
-1200^{*}\end{array}$ & $\begin{array}{c}-5600 \pm 40 \\
(-6000 \pm 60) \\
400^{*}\end{array}$ & $\begin{array}{c}-3300 \pm 170 \\
(-5100 \pm 170) \\
1800^{*}\end{array}$ \\
\hline 3-phenyl-1-propanol & $\begin{array}{c}-14700 \pm 70 \\
(-10000 \pm 110) \\
-4700^{*}\end{array}$ & $\begin{array}{c}-11500 \pm 120 \\
(-8700 \pm 100) \\
-2800^{*}\end{array}$ & $\begin{array}{c}-8500 \pm 180 \\
(-7300 \pm 170) \\
-1200^{*}\end{array}$ & $\begin{array}{c}-6100 \pm 80 \\
(-6500 \pm 80) \\
400^{*}\end{array}$ & $\begin{array}{c}-3600 \pm 60 \\
(-5400 \pm 50) \\
1800^{*}\end{array}$ \\
\hline Propylbenzene & $\begin{array}{c}-20500 \pm 50 \\
(-8900 \pm 30) \\
-11600^{*}\end{array}$ & $\begin{array}{c}-16900 \pm 110 \\
(-7900 \pm 70) \\
-9000^{*}\end{array}$ & $\begin{array}{c}-13400 \pm 80 \\
(-6800 \pm 90) \\
-6600^{*}\end{array}$ & $\begin{array}{c}-10000 \pm 80 \\
(-5700 \pm 70) \\
-4300^{*}\end{array}$ & $\begin{array}{c}-6100 \pm 140 \\
(-4200 \pm 140) \\
-1900^{*}\end{array}$ \\
\hline Butylbenzene & $\begin{array}{c}-23500 \pm 50 \\
(-9900 \pm 30) \\
-13600^{*}\end{array}$ & $\begin{array}{c}-19500 \pm 90 \\
(-8800 \pm 60) \\
-10700^{*}\end{array}$ & $\begin{array}{c}-15500 \pm 130 \\
(-7600 \pm 130) \\
-7900^{*}\end{array}$ & $\begin{array}{c}-11600 \pm 90 \\
(-6400 \pm 90) \\
-5200^{*}\end{array}$ & $\begin{array}{c}-7200 \pm 170 \\
(-4600 \pm 170) \\
-2600^{*}\end{array}$ \\
\hline
\end{tabular}

${ }^{a}$ The reproducibility was better at lower methanol contents in the mobile phase, and gets worse at higher methanol contents. Thus only 2 repeated measurements were made for data of low methanol contents, and 3-4 measurements were made for data of high methanol contents. 


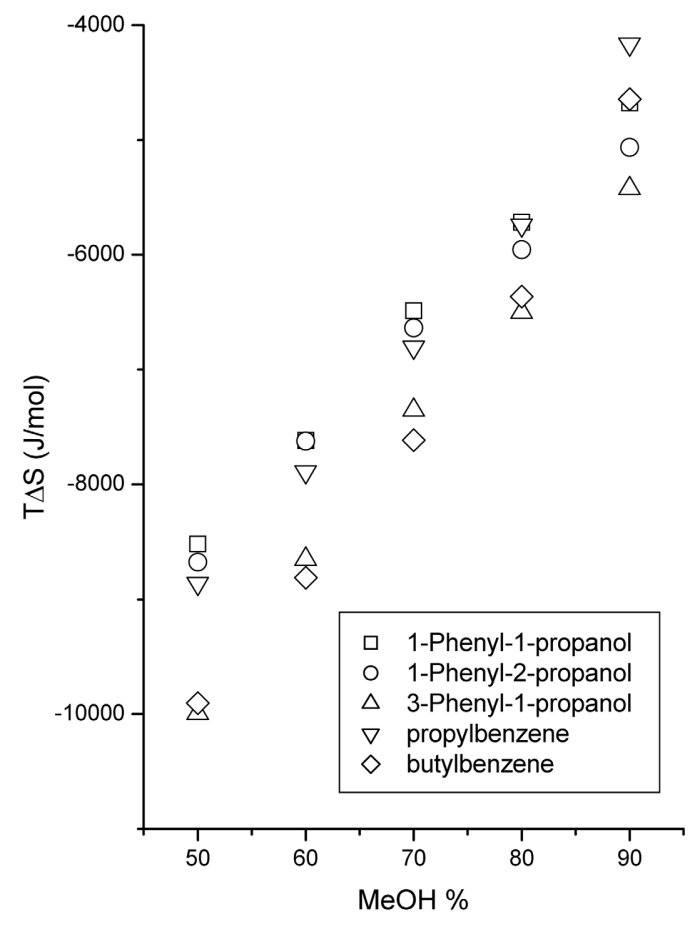

Figure 2. The solute transfer entropies.

study. ${ }^{18}$ We also note that the difference between secondary alcohols (1-phenyl-1-propanol and 1-phenyl-2-propanol) is negligible compared to the difference between the primary alcohol (1-phenyl-3-propanol) and secondary alcohols (Figure 1). This is due to the fact that the hydrogen bond accepting ability of secondary alcohol is larger than that of primary alcohol. ${ }^{18}$

The trend of difference in $\mathrm{T} \Delta \mathrm{S}^{\circ}$ between the primary alcohol and secondary alcohols is interesting. The $\mathrm{T} \Delta \mathrm{S}^{\mathrm{o}}$ values of 3-phenyl-1-propanol are close to those of butylbenzene while the $\mathrm{T} \Delta \mathrm{S}^{\circ}$ values of secondary alcohols are close to those of propylbenzene (Figure 2). In other words, a terminal hydroxyl group may act like a methyl group in entropy contribution while the entropy contribution of a non-terminal hydroxyl group is negligible. The more negative $\mathrm{T} \Delta \mathrm{S}^{\mathrm{o}}$ values of 3-phenyl-1-propanol compared to those of secondary alcohols imply that the entropy of 3phenyl-1-propanol in the mobile phase is higher than those of secondary alcohols if it is assumed that the entropy is basically identical for all the phenylpropanol isomers in the nonpolar stationary phase. The higher freedom of 3-phenyl1-propanol in the polar mobile phase may be due to easier accessibility of solvent molecules to the terminal hydroxyl group and its easier motion in the mobile phase compared to the non-terminal hydroxyl group.

The solute transfer free energies. The solute transfer free energies from the mobile to the stationary phase were calculated as $\Delta \mathrm{G}^{\mathrm{o}}=\Delta \mathrm{H}^{\mathrm{o}}-\mathrm{T} \Delta \mathrm{S}^{\mathrm{o}}$, and added to Table $1 . \Delta \mathrm{G}^{\mathrm{o}}$ values are denoted by an asterisk.

Considering 3 isomeric alcohols, we can note that the differences in $\Delta \mathrm{G}^{\circ}$ among positional isomers are smaller than those in $\Delta \mathrm{H}^{\mathrm{o}}$ owing to a canceling effect of $\mathrm{T} \Delta \mathrm{S}^{\mathrm{o}}$

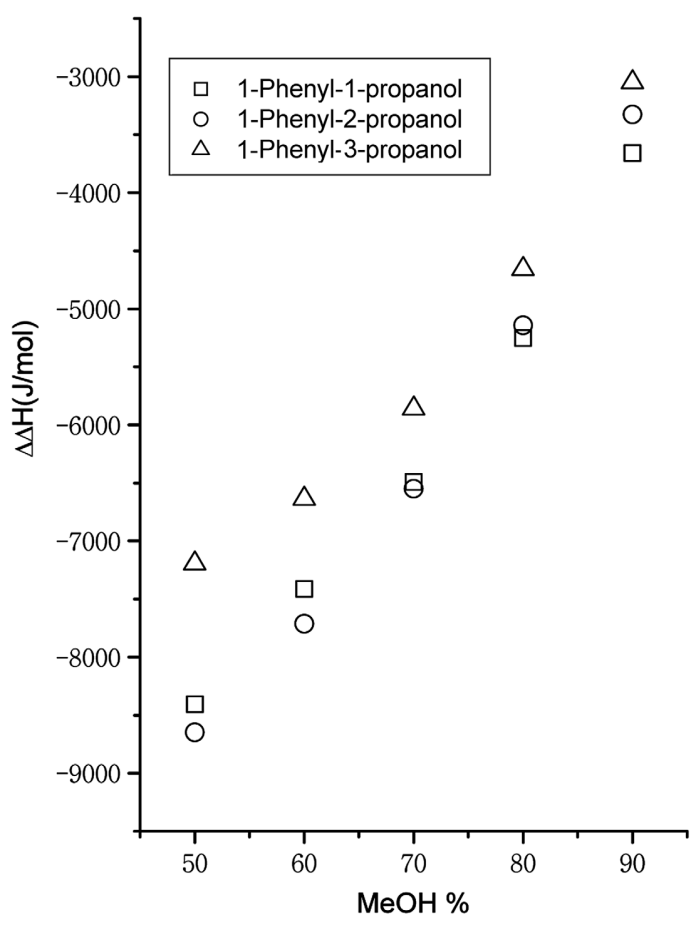

Figure 3. Differential solute transfer enthalpies. See text for details.

against $\Delta \mathrm{H}^{\mathrm{o}}$. Such trend is more obvious as the methanol content in the mobile phase increases.

The solute functional group-mobile phase specific interaction enthalpies and entropies. Now let us examine the differential solute transfer enthalpies and entropies between a pair of solutes (a polar solute with a functional

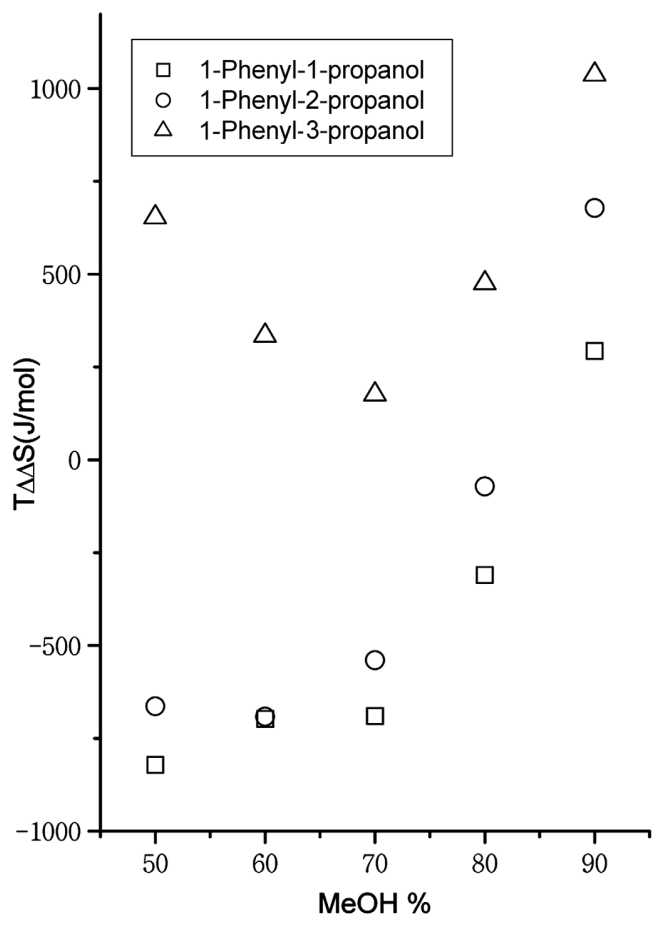

Figure 4. Differential solute transfer entropies. See text for details. 
group and a hypothetical alkylbenzene whose size and shape are exactly the same as the polar solute). Such results are shown in Figures 3 and 4 . The differential solute transfer enthalpy is equal to the specific functional group-mobile phase interaction enthalpy if the solute retention follows a perfect partition mechanism. ${ }^{14}$

The thermodynamic relationship between the capacity factor $\left(k^{\prime}\right)$ and temperature (T) has been well known as follows:

$$
\ln k^{\prime}=-\Delta \mathrm{H}^{\circ} /(\mathrm{RT})+\Delta \mathrm{S}^{\mathrm{o}} / \mathrm{R}+\ln \phi
$$

where $\Delta \mathrm{H}^{\circ}$ and $\Delta \mathrm{S}^{\circ}$ are the standard enthalpy and entropy for the solute transfer from the mobile phase to the stationary phase, respectively, $\phi$, the phase ratio, and $\mathrm{R}$, the gas constant. If $\Delta \mathrm{H}^{\circ}$ and $\Delta \mathrm{S}^{\mathrm{o}}$ are independent of temperature, the plot of $\ln k^{\prime}$ vs. 1/T (van't Hoff plot) will be linear, and we can compute $\Delta \mathrm{H}^{\circ}$ from the slope, and $\Delta \mathrm{S}^{\circ}$ from the intercept.

The selectivity $\alpha$ of a column for the two solutes A and B is defined as the ratio of the capacity factors.

$$
\alpha=k_{\mathrm{A}}{ }^{\prime} k_{\mathrm{B}}{ }^{\prime}
$$

We can easily derive the following equation by writing two equations of (1) type for the solute $\mathrm{A}$ and $\mathrm{B}$ and by subtracting the equation for the solute $\mathrm{A}$ from the equation for the solute B.

$$
\ln \alpha=-\Delta \Delta \mathrm{H}^{\circ} /(\mathrm{RT})+\Delta \Delta \mathrm{S}^{\circ} / \mathrm{R}
$$

In equation (3), $\Delta \Delta \mathrm{H}^{\circ}$ means $\Delta \mathrm{H}^{\circ}{ }_{\mathrm{A}}-\Delta \mathrm{H}^{\circ}{ }_{\mathrm{B}}$, and $\Delta \Delta \mathrm{S}^{\circ}, \Delta \mathrm{S}^{\circ}{ }_{\mathrm{A}^{-}}$ $\Delta \mathrm{S}_{\mathrm{B}}^{\mathrm{o}}$, respectively.

If we consider a pair of polar and nonpolar solutes which are of the same size and shape except for a polar functional group, the natural logarithm of the selectivity of the two solutes is proportional to the difference in Gibbs free energy of solute transfer from the mobile phase to the stationary phase. If we assume that the stationary phase is nonpolar and capable of only dispersive interactions, the solute-stationary phase interactions are identical for the pair of solutes. Then the natural logarithm of the selectivity corresponds to the difference in solute-mobile phase interactions between the pair of solutes, and consequently to the nondispersive functional group-solvent (mobile phase) interaction since the dispersive solute-solvent interactions are identical for molecules of the same size and the nonpolar solutes experiences only dispersive interactions in the mobile phase.

$$
\begin{gathered}
\Delta \Delta \mathrm{G}^{\mathrm{o}}=\Delta \mathrm{H}_{\mathrm{f}-\mathrm{s}}^{\mathrm{o}}-\mathrm{T} \Delta \mathrm{S}_{\mathrm{f}-\mathrm{s}}^{\mathrm{o}} \\
\ln \alpha=-\Delta \mathrm{H}_{\mathrm{f}-\mathrm{s}}^{\mathrm{o}} /(\mathrm{RT})+\Delta \mathrm{S}_{\mathrm{f}-\mathrm{s}}^{\mathrm{o}} / \mathrm{R}
\end{gathered}
$$

$\Delta \mathrm{H}^{\mathrm{o}}{ }_{\mathrm{f}-\mathrm{s}}$ and $-\mathrm{T} \Delta \mathrm{S}_{\mathrm{f}-\mathrm{s}}^{\mathrm{o}}$ are the enthalpic and entropic contributions to the Gibbs free energy of nondispersive functioal group-solvent interaction in the mobile phase. From equations (3) and (5), $\Delta \mathrm{H}^{\mathrm{o}}$ f-s and $-\mathrm{T} \Delta \mathrm{S}_{\mathrm{f}-\mathrm{s}}^{\mathrm{s}}$ are equal to $\left.\Delta \Delta \mathrm{H}^{\circ} / \mathrm{RT}\right)$ and $-\mathrm{T} \Delta \Delta \mathrm{S}^{\circ}$, respectively. The cavity formation free energies in a phase are identical for the pair of solutes of the same size and their contributions to the overall free energies of solute transfer $\left(\Delta \mathrm{G}_{\mathrm{A}}^{\mathrm{o}}\right.$ and $\left.\Delta \mathrm{G}_{\mathrm{B}}^{\mathrm{o}}\right)$ are canceled out when the difference $\left(\Delta \Delta \mathrm{G}^{\mathrm{o}}=\Delta \mathrm{G}_{\mathrm{A}}^{\mathrm{o}}-\Delta \mathrm{G}_{\mathrm{B}}^{\mathrm{o}}\right)$ is obtained. Thus, we can compute $\Delta \mathrm{H}_{\mathrm{f}-\mathrm{s}}^{\mathrm{s}}$ and $\Delta \mathrm{S}_{\mathrm{f} \text {-s }}^{\mathrm{o}}$ by plotting $\ln \alpha$ against 1/T and measuring the slope and intercept.

The solute molecules are much larger than solvent molecules (water and methanol), thus the solute hydroxyl group will have a higher electron density (induction effect) than the solvent hydroxyl group. Therefore, the solute hydroxyl group will prefer accepting hydrogen bond to donating hydrogen bond, and the contribution of hydrogen bond formation where the solute hydroxyl group donates hydrogen bond to solvent molecules, will be much less important. Hydrogen bond donating ability of water is greater than that of methanol for the same reason and $\Delta \Delta \mathrm{H}^{\circ}$ gets more negative as the water content in the mobile phase increases (Figure 3). The difference in $\Delta \Delta \mathrm{H}^{\circ}$ between the primary alcohol (1-phenyl-3-propanol) and secondary alcohols (1-phenyl-1-propanol and 1-phenyl-2-propanol) decreases with increase of methanol content in the mobile phase. This is consistent with the fact that the hydrogen bond accepting ability of secondary alcohols is larger than that of primary alcohol. The $\mathrm{O}$ atom of of a secondary alcohol will have higher electron density (stronger hydrogen bond accepting ability) due to the stronger inductive effect of dual substituents than the $\mathrm{O}$ atom of a primary alcohol of single substituent. Hydrogen bond donating ability of methanol/ water mixture becomes weaker as the methanol content gets higher. The hydrogen bond strength is proportional to the solvent hydrogen bond donating ability times the solute hydrogen bond accepting ability. Thus increase of methanol content in the solvent will decrease the magnitude of hydrogen bond strength between any phenylpropanol and the solvent and differences in solute-solvent hydrogen bond strength among the phenylpropanols as well.

$\Delta \Delta \mathrm{S}^{\mathrm{o}}$ is more difficult to analyze. It is a delicate function of some entangled factors such as the solute size and shape, the type and position of the functional group, the type and strength of the specific solute-solvent interactions, etc., in the mobile and stationary phases. Furthermore, $T \Delta \Delta \mathrm{S}^{\circ}$ is much less significant compared to $\Delta \Delta \mathrm{H}^{\circ}$. The absolute magnitude of $\mathrm{T} \Delta \Delta \mathrm{S}^{\circ}$ is at best less than $30 \%$ of that of $\Delta \Delta \mathrm{H}^{\circ}$. Anyway, there is a clear positional effect of functional group on the magnitude of $\Delta \Delta \mathrm{S}^{\circ}$ as shown in Figure 4.

A clear mininum for 1-phenyl-3-propanol in the plot of $\mathrm{T} \Delta \Delta \mathrm{S}^{\circ} v$ s. methanol volume \% (Figure 4) was observed at $70 \%$. A vague minimum was observed for 1-phenyl-2propanol at $60 \%$. Due to our experimental limitations, we could not measure $\mathrm{T} \Delta \Delta \mathrm{S}^{\circ}$ for concentration below $50 \%$. There is possibility of a minimum for 1-phenyl-1-propanol in concentration below $50 \%$. The clear minimum of 1phenyl-3-propanol was caused by the fact that the $T \Delta S^{\circ}$ value of 3-phenyl-1-propanol is below the $\mathrm{T} \Delta \mathrm{S}^{\circ}$ value of butylbenzene at $50 \%$ methanol, above at $60-70 \%$ methanol, and below again at $80-90 \%$ methanol (Figure 2). In the previous study, ${ }^{18}$ 4-phenyl-1-butanol(primary alcohol like 3phenyl-1-propanol of this study) did not show such a trend. It is probably because the data for 4-phenyl-1-butanol was limited to 70-90 methanol\% for its long retention time.

The positive sign and extremum of $\mathrm{T} \Delta \Delta \mathrm{S}^{\circ}$ of 3-phenyl-1- 
propanol of Figure 4 imply that the entropy of 3-phenyl-1propanol is greater than that of the hypothetical alkylbenzene (the same size as phenylpropanol) in the mobile phase and the entropy difference is minimized at $70 \%$ methanol if it is assumed that the entropies of 3-phenyl-1propanol and the hypothetical alkylbenzene are virtually identical in the nonpolar stationary phase and invariant with respect to mobile phase composition.

The higher freedom of 3-phenyl-1-propanol in the polar mobile phase may be due to easier accessibility of solvent molecules to the terminal hydroxyl group and its easier motion in the mobile phase. It is not clear, however, why the motional freedom of 3-phenyl-1-propanol relative to the hypothetical alkylbenzene is minimized at the mobile phase composition of $70 \%$ methanol. Molecular dynamics calculation or Monte Carlo simulation could help understand the phenomenon, which is above the scope of this study.

\section{Conclusion}

The specific solute functional group-mobile phase interaction enthalpies and entropies for positional isomers of phenylpropanols have been estimated based on retention data obtained by a $\mathrm{C}_{18}$ stationary phase. There exists a clear positional effect on the magnitude of specific functional group-solvent interaction. The analysis of enthalpic data leads to the fact that the hydrogen bond accepting ability of secondary alcohols is larger than that of primary alcohol and that increase of methanol content in the solvent will decrease the magnitude of hydrogen bond strength between all the phenylpropanols and the solvent and differences in hydrogen bond strength among the phenylpropanols as well. The analysis of entropic data reveals that a terminal hydroxyl group may act like a methyl group in entropy contribution while the entropy contribution of a non-terminal hydroxyl group is negligible. The higher freedom of 3-phenyl-1propanol in the polar mobile phase may be due to easier accessibility of solvent molecules to the terminal hydroxyl group and its easier motion in the mobile phase.

Acknowledgement. This work was supported by the 2004 Inha University Fund.

\section{References}

1. Grushka, E.; Colin, H.; Guichon, G. Anal. Chem. 1982, 248, 325.

2. Issaq, H. J.; Jaroniec, M. J. Liq. Chromatogr. 1989, 12, 2067.

3. Cole, L. A.; Dorsey, J. G. Anal. Chem. 1992, 64, 1317.

4. Cole, L. A.; Dorsey, J. G.; Dill, K. A. Anal. Chem. 1992, 64, 1324.

5. Alvarez-Zepeda, A.; Barman, B. N.; Martire, D. E. Anal. Chem. 1992, 64, 1978.

6. Tchapla, A.; Heron, S.; Colin, H.; Guichon, G. Anal. Chem. 1988, 60, 1443.

7. Yamamoto, F. M.; Rokushika, S.; Hatano, H. J. Chromatogr. Sci. 1989, 27, 704

8. Sander, L. C.; Field, L. R. Anal. Chem. 1980, 52, 2009.

9. Bell, C. M.; Sander, L. C.; Wide, S. A. J. Chromatogr. A 1997, $757,29$.

10. McGuffin, V. L.; Chen, S. J. Chromatogr. A 1997, 762, 35.

11. Miyabe, K.; Suzuki, M. AIChE J. 1995, 41, 548.

12. Miyabe, K.; Takeuchi, S. Anal. Chem. 1997, 69, 2567.

13. Guillaume, Y.; Guinchard, C. J. Liq. Chromatogr. 1994, 17, 2807.

14. Lee, C. S.; Cheong, W. J. J. Liq. Chrom. \& Rel. Technol. 1999, 22, 253.

15. Lee, C. S.; Cheong, W. J. J. Chromatogr. A 1999, 848, 9.

16. Cheong, W. J.; Kim, C. Y.; Koo, Y. M. Bull. Korean Chem. Soc. 2000, 21, 105

17. Cheong, W. J.; Kim, C. Y. Bull. Korean Chem. Soc. 2000, 21, 351.

18. Cheong, W. J.; Keum, Y. I. J. Chromatogr. A 2001, 910, 195. 